\title{
The role of mobile technologies in shifting to digital
}

\author{
Hale Ilgaz ${ }^{1}$ \\ Published online: 2 February 2021 \\ (c) Association for Educational Communications and Technology 2021
}

\begin{abstract}
In this section, we have responses to Joo, Kim and Kim (2016)'s study, from two scholars with international and inclusion perspectives. They have discussed the current situation with mobile learning management systems and the current mobile learning experiences.
\end{abstract}

Keywords Mobile learning · Accessiblity · Equity

Mobile learning (m-learning) can be seen as a popular and accessible technology to support online learning. Mobile devices make education more accessible anytime and anywhere. That is highly attractive, but also has limitations for its adoption and usage. Joo et al. (2016) have focused on online university students' actual usage of a mobile learning management system based on the relationships among factors of influence. In this special issue, we have responses from two scholars in the context of international and inclusion perspectives.

Dr. Elen has presented his perspective with an international point of view. He put the importance of mobile devices by their role during the emergent remote teaching process. And he especially focused on the portability and availability features. By comparison to the other devices, mobile devices have been accessible by the vast majority of both learners and teachers and specifically they have been used during the pandemic as the primary tool for the emergent remote teaching process.

Dr. Antee has approached the Joo et al. (2016) article from an inclusion perspective. She has focused on general features like levels of income, country statuses, or digital skills of the learners. She has presented some design and practical solutions to overcome the affordances of mobile devices.

In today's world, speed, accessibility and mobility are important themes of human lives. Mobile devices and mobile compatible applications have an important role in this educational digital shift. In addition to the accessibility, ease of use, and speed features, design issues should also be considered. For a successful learning process, researchers and practitioners should define mobile learning environments and tools' unique functions and affordances (Grant 2019).

Hale Ilgaz

hilgaz@ankara.edu.tr

1 Faculty of Open and Distance Education, Ankara University, Ankara University Besevler Yerleskesi, 06100 Ankara, Turkey 


\section{Reference}

Grant, M. M. (2019). Difficulties in defining mobile learning: Analysis, design characteristics, and implications. Educational Technology Research and Development, 67, 361-388. https://doi.org/10.1007/s1142 3-018-09641-4.

Joo, Y. J., Kim, N., \& Kim, N. H. (2016). Factors predicting online university students' use of a mobile learning management system (m-LMS). Educational Technology Research and Development, 64, 611630. https://doi.org/10.1007/s11423-016-9436-7.

Publisher's Note Springer Nature remains neutral with regard to jurisdictional claims in published maps and institutional affiliations.

Hale Ilgaz is an Associate Professor in the Faculty of Open and Distance Education at Ankara University. Her main research areas are distance education, e-learning, instructional design, cognitive processes in e-learning environments, cognitive psychology, and human-computer interaction. 